\title{
O Instrumento Bateria
} The Drum set Instrument

Cesar Adriano Traldi ${ }^{1}$

Thiago de Souza Ferreira ${ }^{2}$

ISSN: 1808-3129 


\section{Resumo}

A bateria é um instrumento da família da percussão. Entretanto, existe uma grande discussão se quando utilizamos a palavra bateria, estamos nos referindo literalmente a um instrumento ou a um conjunto de instrumentos de percussão. É consenso que a bateria é formada por vários instrumentos de percussão, entretanto, encontramos pessoas que encaram a bateria como sendo um instrumento independente da percussão e outras que apontam para a bateria como um set-up de percussão múltipla. Assim, o objetivo dessa pesquisa é analisar características históricas e interpretativas da bateria e do set-up de percussão múltipla buscando identificar características que realmente podem colocar a bateria nesse status de instrumento independente da percussão. Apresentamos o conceito de técnica estendida e técnica tradicional e em seguida um breve histórico do surgimento da percussão múltipla e da bateria. Os resultados alcançados apontam que a bateria possui técnicas e funções musicais extremamente particulares que a diferenciam da percussão múltipla.

Palavras-Chave: bateria, percussão múltipla, técnica estendida.

\section{Abstract}

The drum set is from the percussion instrument family. However, there is a big discussion whether the use of the name drum set literally means one instrument or a set of percussion instruments. The consensus is that the drum set is composed of various percussion instruments, though we find people who view the drum set as an independent percussion instrument, and yet others who describe the drum set as a set-up of multiple percussion. The objective of this research is to analyze historical and interpretive characteristics of both the drum set and the set-up of multiple percussion seeking to identify features that can really put the drum set in the status of independent percussion instrument. We present the concept of extended technique versus traditional technique and then a brief history of the emergence of multiple percussion as well as the drum set. The results achieved indicate that the drum set has technical and extremely particular musical features which make it distinct from multiple percussion.

Keywords: drum set, multiple percussion, extended technique.

\footnotetext{
${ }^{1}$ Pesquisador do Núcleo de Música e Tecnologia e professor da Universidade Federal de Uberlândia.

Uberlância - MG - Brasil

ctraldi@hotmail.com
}

${ }^{2}$ Mestrando em Música na Universidade Federal de Uberlândia.

Uberlância - MG - Brasil

justapird@hotmail.com 


\section{INTRODUÇÃO}

A bateria é formada por um conjunto de instrumentos de percussão e assim pertence à essa família. Entretanto, apesar do seu surgimento recente, final do século XIX - início do século XX, ela tem sido tratada como um instrumento independente. Isso é facilmente notado pela existência de cursos de diversos níveis (técnico, superior, etc.) que focam o ensino da bateria independente da percussão. Apesar de alguns bateristas tocarem percussão e alguns percussionistas tocarem bateria, não podemos dizer que isso é uma regra. De maneira geral, o estudo e performance desses instrumentos é realizado de maneira separada. Assim, hoje temos os bateristas e os percussionistas, duas classes de músicos intérpretes diferentes e independentes.

Entretanto, quando olhamos para o surgimento da bateria, vemos que ela tem suas origens na percussão. Segundo Barsalini "A bateria é um instrumento múltiplo, ou seja, consiste em uma junção de diferentes instrumentos de percussão, e executado de forma preponderante na música popular." (Barsalini, 2009, p.09) Carinci define que "a bateria é uma coleção de outros instrumentos. Mas ao serem agrupados, reunidos, estes diversos instrumentos de origens e tradições também diversas, passaram a se configurar como um só instrumento, tocado pelo mesmo músico, no formato do que é a bateria que conhecemos hoje." (Carinci, 2012, p.25)

Assim, essa pesquisa busca estudar e clarear quais são as reais diferenças entre bateria e percussão múltipla e verificar quais são as características que fizeram com que a bateria ganhasse esse patamar de instrumento "independente" da percussão. Para isso, apresentaremos as definições de técnica tradicional e técnica estendida, conceitos essenciais para entendermos as diferenças técnicas entre eles. Em seguida, apresentamos um histórico do surgimento da percussão múltipla e da bateria. E por fim, refletimos sobre as principais diferenças entre bateria e percussão múltipla e concluímos que realmente existem diferenças importantes. 


\section{TÉCNICA TRADICIONAL E TÉCNICA ESTENDIDA}

Para a discussão aqui apresentada é extremamente importante entendermos claramente o que são as técnicas tradicionais e técnicas estendidas ${ }^{1}$ de um instrumento.

A técnica tradicional de um instrumento é aquela consolidada pela prática e por sua utilização no repertório consagrado do instrumento. Entretanto, dentro da técnica tradicional podem existir diferentes possibilidades de execução, por exemplo, no violino uma das técnicas tradicionais de se tocar o instrumento é com o arco, porém, existem diferentes maneiras de se segurar e/ou posicionar o arco pelo intérprete. Nos instrumentos de percussão isso também ocorre, a caixa, por exemplo, é tradicionalmente tocada com baquetas de madeira (chamadas de baquetas de caixa) na região central do instrumento. Esse toque tradicional pode ser realizado com diferentes maneiras de se segurar as baquetas e movimentos de execução. Entre os mais conhecidos estão a maneira tradicional, moeller, alemã e francesa.

A técnica estendida é uma maneira de se tocar que não está consagrada no estudo e repertório desse instrumento e que busca explorar novas sonoridades. Tocar um violino com um prego ou um saxofone sem a boquilha não são técnicas consagradas desses instrumentos. Assim, "pode-se dizer que o termo técnica estendida equivale a técnica não usual: maneira de tocar ou cantar que explora possibilidades instrumentais, gestuais e sonoras pouco utilizadas em determinado contexto histórico, estético e cultural." (PADOVANI; FERRAZ, 2012, p.01) A utilização de técnicas tradicionais de um instrumento em outro pode tornar-se técnica estendida, por exemplo, a utilização de arcos, que é uma técnica tradicional de violinos, violas, violoncelos e contrabaixos, torna-se técnica estendida quando utilizada em um violão, pratos de percussão, etc.

Uma técnica estendida pode tornar-se técnica tradicional a partir do momento em que ela passa a pertencer à linguagem do instrumento e ser utilizada de maneira mais constante em composições e performances. Talvez o exemplo mais comum dessa mudança de técnica estendida para técnica tradicional é a utilização dos pizzicatos nos violinos. Segundo Toffolo "o uso do pizzicato que hoje é uma forma de tocar totalmente usual para os instrumentos de cordas arcadas, foi considerado incomum no início do período Barroco". (TOFFOLO, 2010, p.1280) Tradicionalmente esses instrumentos eram apenas tocados com o arco, em Il Combattimento di Tancredi e Clorinda (1624) o compositor Claudio Monteverdi utilizou pela primeira vez a técnica de pizzicato nos violinos. Naquele momento, a utilização de pizzicato era uma técnica estendida, entretanto, com o passar do tempo, diversos compositores passaram a utilizar essa sonoridade em suas obras. Segundo Padovani e Ferraz essa técnica "se consolidou com o repertório clássico-romântico" (PADOVANI; FERRAZ, 2012 , p.02) e atualmente o pizzicato é visto como uma técnica tradicional dos instrumentos de cordas friccionadas.

Nos instrumentos de percussão a utilização de arcos nos instrumentos de teclado é um exemplo disso. Atualmente, tocar com arcos nos teclados de percussão é algo comum e utilizado em diversas obras musicais. É comum vermos percussionistas terem ar-

1 Alguns textos utilizam o termo técnica expandida para nomear o que aqui tratamos de técnica estendida. 
cos em suas bolsas de baquetas. Assim, podemos dizer que tocar com arco nos teclados de percussão já pode ser considerado técnica tradicional desses instrumentos.

\section{DESENVOLVIMENTO DA PERCUSSÃO MÚLTIPLA NO SÉCULO XX}

Apesar dos instrumentos de percussão estarem entre os mais antigos instrumentos criados pelo ser humano, no repertório ocidental verifica-se uma pequena utilização e exploração de suas capacidades sonoras dentro do repertório Barroco, Clássico e Romântico. Entretanto, "a exploração de vários e não usuais recursos composicionais e técnicos caracterizam o uso da percussão na música do século $\mathrm{XX}$, bem como as melhorias na construção dos instrumentos, e o avanço na técnica de execução pelos músicos" (HASHIMOTO, 2003, p.27)

Entre as inovações técnicas do século XX está a percussão múltipla, "prática em que um executante tem a possibilidade de tocar dois ou mais instrumentos de percussão ao mesmo tempo ou em rápida sucessão." (MORAIS; STASI, 2015, p. 62)

A primeira utilização de percussão múltipla conhecida é a obra de 1918 "A História do Soldado" de Igor Stravinsky. Segundo Morais e Stasi "a origem da percussão múltipla está ligada a problemas de natureza econômica, de escassez de instrumentistas e também, por outro lado, às origens do Jazz e suas influências." (MORAIS; STASI, 2015, p. 64) O pós-guerra foi o fator principal na imposição de uma série de restrições de executantes nesse período. Na obra mencionada de Stravinsky, um único percussionista toca um conjunto de instrumentos de percussão. O compositor finaliza a obra com um solo de percussão que coloca em grande destaque esse instrumento e abre para outros compositores as possibilidades solistas da percussão.

Um importante fator que tornou possível o surgimento da percussão múltipla no século XX é "o fato que, nessa época, muitos instrumentos de percussão estavam em franco desenvolvimento, sendo aprimorados e adaptados às necessidades que então vinham sendo impostas pelas peças para música de câmara e orquestra." (MORAIS; STASI, 2015, p. 67)

O surgimento de acessórios dava novas configurações aos instrumentos, surgindo "novas possibilidades de disposição, de montagem e de combinação (entre mesmos instrumentos ou destes com outros)." (MORAIS; STASI, 2015, p. 67)

\section{O SURGIMENTO DA BATERIA}

Segundo Nichols (2012, p. 09) a performance de percussão em bandas de rua (metal e percussão) no final do século XIX e início do século XX, derivou das práticas orquestrais dos séculos anteriores. Assim, a percussão era tocada por diversos intérpretes onde cada um era responsável pela performance de apenas um instrumento. A formação da percussão mais comum nesse período era bumbo, caixa e prato de choque, ou seja, eram necessários três percussionistas. Segundo o autor, era essa a prática realizada nas bandas de rua de New Orleans. Essa cidade é conhecida como o berço do jazz e naquele momento já era uma referência musical nos 
Estados Unidos com um grande movimento cultural musical e grande abundância de bandas de metal (bandas formadas por instrumentos da família dos metais de sopro e percussão).

Ainda segundo Nichols (2012, p. 09) a popularidade dessas bandas cresceu, aumentando o número de apresentações. Assim, tornou-se um problema gerir um grande número de pessoas e também a parte financeira dessas bandas. Então, os lideres começaram a buscar as mesmas sonoridades com um número menor de intérpretes, o que facilitaria a gestão das bandas e diminuiria o número de pagamentos a serem realizados. Essa busca dos lideres foi somada a um pensamento dos percussionistas que previam que se apenas um intérprete poderia realizar o que três ou mais faziam, o valor do cachê iria aumentar, já que existiriam menos pessoas para a divisão dos valores. Esses dois pensamentos fizeram surgir a adaptação de um grupo de percussão com vários intérpretes em um conjunto de tambores tocados por apenas um músico.

Segundo Reimer (2013, p. 11) entre 1890 e 1910, por motivos econômicos ou por falta de espaço, o líder de banda "Papa Jack" Laine (1873-1966) contratou apenas um percussionista para tocar os instrumentos de percussão e foi um dos responsáveis por popularizar o set-up de tambores tocados por um único intérprete. "A reunião de diferentes instrumentos em um conjunto próprio (na maioria das vezes, específico e exclusivo de uma só peça em questão) é denominada em inglês de set ou set-up (termos muitas vezes utilizados em português também)." (MORAIS; STASI, 2015, p. 63). Esse set-up de tambores posteriormente passou a ser chamado de double drumming.

O double drumming consistia em uma técnica utilizada para tocar dois tambores ao mesmo tempo, ambos os tambores eram tocados com baquetas por um percussionista, o bumbo com a mão direita e a caixa (apoiada em uma cadeira) com a mão esquerda. Segundo Reimer (2013, p. 11) o double drumming passou também a ser utilizado por músicos de teatro, que buscando novas sonoridades e efeitos em suas peformances, passaram a adicionar outros instrumentos de percussão no set-up como xilofones, blocos de madeira, apitos, etc. Com a técnica do double drumming estabelecida, foi inventada a estante regulável para a caixa em 1898 por Ulysses Grant Leedy.

A inclusão de novos instrumentos no set-up e a evolução na técnica de performance, passaram a exigir a utilização das duas mãos de maneira rápida em diversos instrumentos e em algumas passagens a utilização das duas mãos no mesmo instrumento, normalmente a caixa. Assim, alguns músicos passaram a tocar o bumbo com o pé, ou seja, o instrumento era literalmente chutado pelo intérprete. Essa nova possibilidade de performance levou ao desenvolvimento de vários modelos de pedais para tocar o bumbo. Porém, esses pedais eram lentos e pesados e caíram rapidamente em desuso, pois não atendiam as necessidades dos percussionistas que tocavam no estilo ragtime e necessitavam realizar toques rápidos e sincopados no bumbo. Segundo Reimer (2013, p.14) para atender essa demanda musical, Ludwig patenteou em 1909, o primeiro pedal de metal com mola, que permitia que o batedor voltasse à posição inicial depois de cada toque. Assim, esse pedal era mais rápido e proporcionava aos músicos a velocidade necessária. Além disso, os 
intérpretes tinham as mãos livres para tocar a caixa e outros instrumentos, possibilitando que músicos como Baby Dodds (1898-1958) e Zutty Singleton (1898-1975), explorassem essa nova técnica criando maior independência entre pé e mãos e adicionando novos padrões sincopados e polirrítmicos que posteriormente serviriam de base para a linguagem do Jazz. O surgimento do pedal para bumbo é considerado por muitos músicos e historiadores como o marco do surgimento da bateria como um novo instrumento.

Nesse período o set-up formado por bumbo com pedal, caixa em uma estante, prato suspenso sobre o bumbo e outro prato no aro do bumbo (com a possibilidade de ser tocado com o pedal simultaneamente ao bumbo), tornou-se um set-up padronizado entre diversos músicos e passou a ser difundido e exportado para outros locais e países.

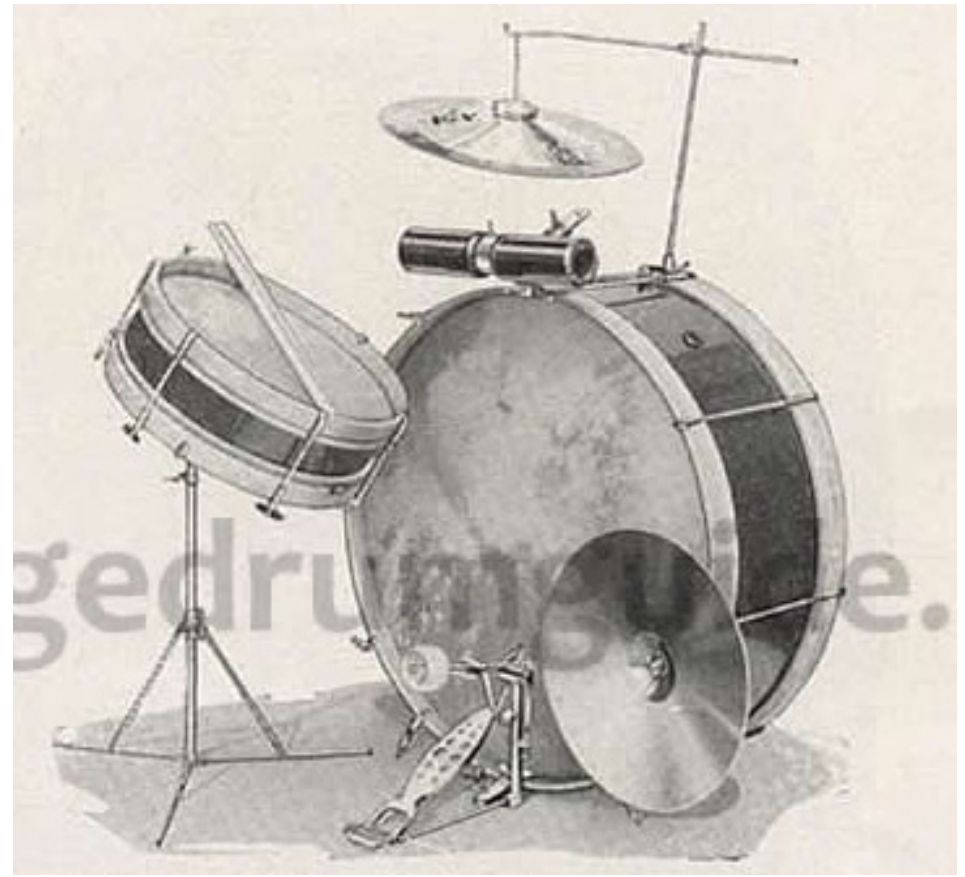

Figura 01: Set-up de bateria do catálogo da Ludwig de 1918. No detalhe, prato acoplado ao bumbo e sistema de pedal (Clanger) que possibilitava a performance do bumbo e do prato simultaneamente.

Fonte: http://www.vintagedrumguide.com/ludwig_drumsets_1918.html. Acesso em 25-10-15.

Como já foi dito, outros instrumentos eram acoplados pelos intérpretes a esse set-up de acordo com a disponibilidade e gosto do intérprete. Segundo Nichols (2012, p. 13) até por volta de 1927, os bateristas estavam usando as mãos e o pé direito para tocar e o pé esquerdo ficava parado. Segundo o autor, os bateristas pensaram em usar o membro que não estava tocando (pé esquerdo) pra fazer o papel dos músicos que tocavam o prato de choque, ou seja, os tempos dois e quatro. Inventores passam a desenvolver um dispositivo a pedal que possibilitasse a performance do prato de choque com o pé esquerdo e assim surgem dois mecanismos conhecidos como Snow-Shoe e o Low-Hat, esses dois dispositivos levaram posteriormente ao desenvolvimento do Hi-Hat (máquina de chimbal ${ }^{2}$ ) utilizada até hoje. Segundo Reimer (2013, p.15) as frustrações dos bateristas Sonny Greer (1898 - 1982) e 'Papa' Jo 
Jones (1911-1985) com as limitações do Low-Hat, por deixarem os pratos em uma altura impossível de serem tocados com as baquetas, levaram a criação do Hi-Hat.
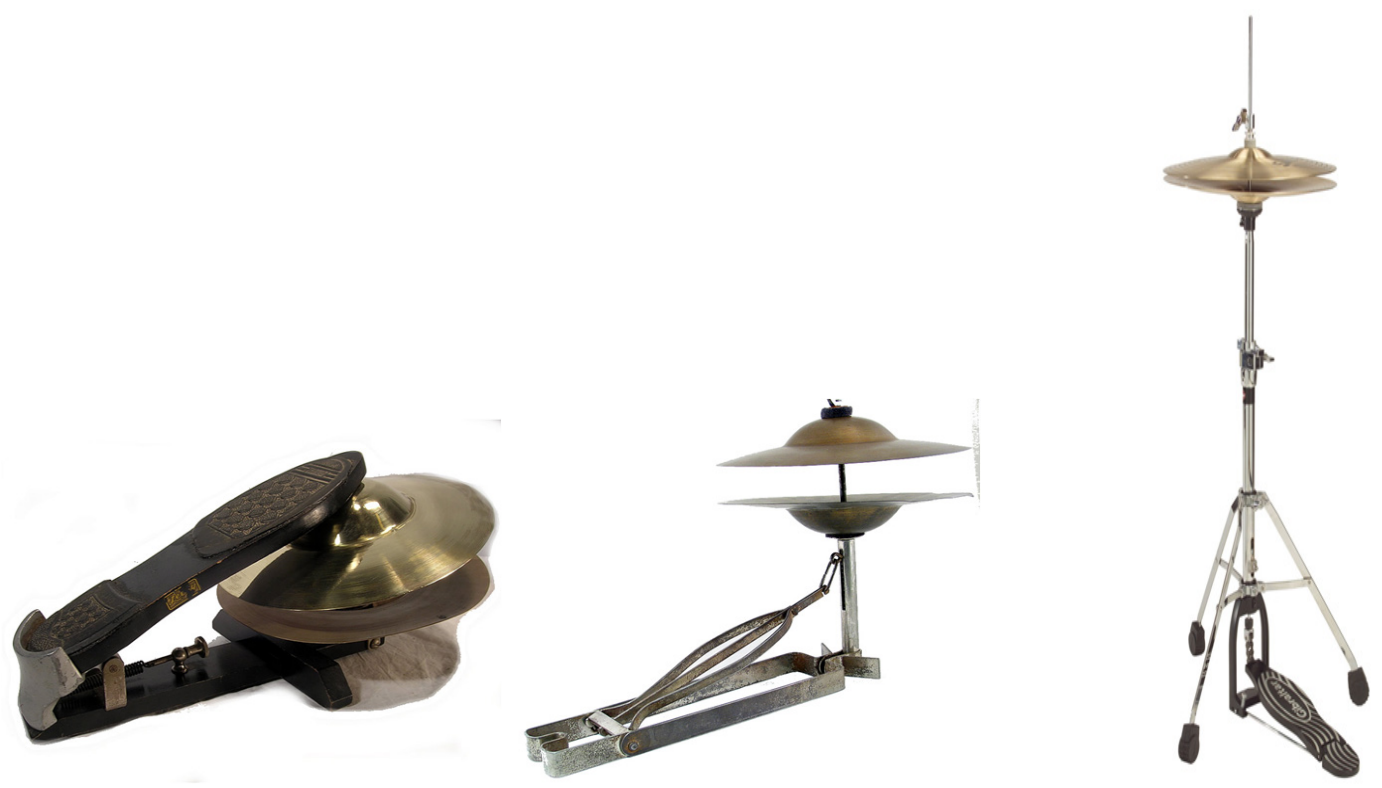

Figura 02 - Da esquerda para a direita os mecanismos Snow-Shoe, Low-Hat e Hi-Hat. Fonte: http://www.vintagedrumguide.com/pedals.html. Acesso em 25-10-2015.

O set-up de bumbo com pedal, caixa em uma estante, prato suspenso e $\mathrm{Hi}$ -Hat tornou-se o padrão de montagem da bateria que persiste até os dias atuais. Atualmente, esse set-up é tradicionalmente implementado também com tambores (ton-tons e surdo), entretanto, existe uma grande variedade de sets utilizados pelos bateristas com diferentes números e tamanhos de tambores e implementação de acessórios como: cowbell, tamborim, blocos sonoros, pratos de diferentes tamanhos e modelos, etc.

Reimer define que a performance no set-up de bateria seria "o uso da independência coordenada com as duas mãos e os pés, em uma junção de tambores e pratos, incluindo, mas não limitado a, bumbo com pedal, caixa e chimbau, criado para ser tocado por uma pessoa"3. (REIMER, 2013, pg. 6).

Além da grande variedade de acessórios para a bateria (normalmente adaptações de instrumentos de percussão) existem diferentes baquetas que possibilitam a exploração de uma gama muito grande de sonoridades, como baquetas com ponta de feltro, as vassourinhas, o ruth, etc.

\section{REFLEXÕES E CONCLUSÕES}

A bateria claramente surgiu dos instrumentos de percussão, entretanto, o conceito que a bateria trata-se de um set-up de percussão múltipla, muitas vezes passa a ideia errada de que a bateria surgiu da percussão múltipla.

\footnotetext{
3 No original: The use of coordinated independence with both hands and feet on a collection of drums and cymbals, including but not limited to, bass drum with pedal, snare drum and hi-hat, set up for convenient playing by one person.
} 
A bateria teve sua origem nas bandas de rua em New Orleans no final do século XIX e a função dos percussionistas nesse tipo de formação era claramente a de marcação rítmica. Assim, o surgimento do double drumming e em seguida a bateria, mantiveram essa característica de marcação rítmica.

Além disso, podemos notar que a performance do double drumming e em seguida a performance da bateria são realizadas com o que poderia ser considerado técnicas estendidas nos instrumentos de percussão. Tocar um bumbo com baquetas de madeira pequenas ou mesmo posteriormente com o pedal, colocar a caixa em um suporte e tocá-la sem estar acoplada ao corpo e tocar o prato de choque com um pedal, são alguns exemplos de técnicas que eram técnicas estendidas para os instrumentos de percussão naquela época. Entretanto, quando olhamos para a performance da bateria, notamos que o que seria técnica estendida para a percussão tornou-se a técnica tradicional da bateria. Ou seja, tocar o bumbo com pedal é a técnica tradicional da bateria e tocar o bumbo com uma baqueta pode ser considerado técnica estendida na bateria.

Fica claro duas características marcantes que diferem a bateria da percussão múltipla:

1. A bateria tradicionalmente desempenha uma função de marcação rítmica, enquanto a percussão múltipla possui um caráter mais solista.

2. A bateria é formada por instrumentos de percussão, entretanto, algumas das técnicas tradicionais aplicadas na bateria podem ser consideradas como técnicas estendidas para os instrumentos de percussão.

Essas características criam tamanha diferença na performance desses dois instrumentos que surgem especialistas em bateria, ou seja, surgem os bateristas e não mais percussionistas. Esses intérpretes se especializaram nas técnicas de execução da bateria desenvolvendo e ampliando as possibilidades técnicas e sonoras desse instrumento durante o século XX e levando a performance a níveis altíssimos.

A primeira obra para percussão múltipla é de 1918 e como já foi dito, "a origem da percussão múltipla está ligada a problemas de natureza econômica, de escassez de instrumentistas e também, por outro lado, às origens do Jazz e suas influências." (MORAIS; STASI, 2015, p. 64) Se olharmos para a história da bateria, veremos que em 1918 ela já estava bem desenvolvida com quase 10 anos do surgimento do pedal de bumbo e em ampla utilização no Jazz. Assim, fica evidente que a percussão múltipla surgiu de influências da bateria.

Essas diferenças levantadas mostram que apesar da bateria ser derivada da percussão e por conceito ser um set-up de percussão múltipla, a sua performance com técnicas extremamente particulares e a função musical característica de marcação rítmica, são elementos que realmente colocam a bateria em condição de diferença da percussão múltipla e com o status de instrumento independente. 


\section{REFERÊNCIAS BIBLIOGRÁFICAS}

BARSALINI, Leandro. As sínteses de Edison Machado: um estudo sobre o desenvolvimento de padrões de samba na bateria. 2009. 172p. Dissertação (Mestrado em Música) - Instituto de Artes, Universidade Estadual de Campinas, Campinas, 2009.

CARINCl, Enrico Joseph. Técnica estendida na performance de bateristas brasileiros. 2012. 108p. Dissertação (Mestrado em Música) - Escola de música e Artes Cênicas UFG, Goiânia, 2012.

HASHIMOTO, Fernando A. de A. Análise musical de "Estudo para instrumentos de percussão", 1953, M. Camargo Guarnieri; primeira peça escrita somente para instrumentos de percussão no Brasil. Campinas, 2003. Dissertação (Mestrado em Música) - Instituto de Artes - UNICAMP.

HENRIQUE PADOVANI E SILVIO FERRAZ, José. Proto-história, Evolução e Situação Atual das Técnicas Estendidas na Criação Musical e na Performance. , [S.l.], v. 11, n. 2, dez. 2012. ISSN 2317-6776. Disponível em: <http://www.revistas.ufg.br/index. $\mathrm{php} / \mathrm{musica} /$ article/view/21752/12804>. Acesso em: 16 Out. 2015. doi:10.5216/mh. v11i2.21752.

MORAIS, Ronan Gil de; STASI, Carlos. Múltiplas faces: surgimento, contextualização histórica e características da percussão múltipla. OPUS - Revista Eletrônica da ANPPOM, Porto Alegre, RS, v. 16, n. 2, p. 61-79, Mai. 2015. ISSN 1517-7017. Disponível em: $\quad$ <http://www.anppom.com.br/revista/index.php/opus/article/view/218/198>. Acesso em: 16 Out. 2015.

NICHOLS, Kevin A. Important works for drum set as a multiple percussion instrument. 2012, 130p. Tese (Doutorado em Música) - Universidade de lowa, 2012.

REIMER, Benjamin N. Defining the Role of Drumset Performance in Contemporary Music. 2013. 108p. Tese (Doutorado em Música, Performance) - Universidade McGil, Quebec, Montreal, 2013.

TOFFOLO, Rael Bertarelli G. Considerações sobre a técnica estendida na performance e composição musical. In: CONGRESSO DA ASSOCIAÇÃO NACIONAL DE PESQUISA E PÓS-GRADUAÇÃO EM MÚSICA, 20., 2010, Florianópolis. Anais.... Florianópolis, 2010, p. $1280-1285$. 